\title{
Potassium ions modulate expression of mouse sperm fertilizing ability, acrosome reaction and hyperactivated motility in vitro
}

\author{
Lynn R. Fraser \\ Department of Human Biology, Chelsea College, Manresa Road, London SW3 6LX, U.K.
}

\begin{abstract}
Summary. In $\mathrm{K}^{+}$-free medium, epididymal sperm suspensions, whether washed free of epididymally-derived $\mathrm{K}^{+}$or not, were unable to penetrate washed cumulus masses; some penetration of zona-free eggs was obtained with unwashed sperm suspensions, while washed samples were generally non-fertilizing. Within $5 \mathrm{~min}$ of $\mathrm{K}^{+}$introduction, however, spermatozoa were able to fertilize intact eggs rapidly and synchronously, indicating that $\mathrm{K}^{+}$was not required for capacitation. Measurements of extracellular $\mathrm{K}^{+}$concentrations in these experiments indicate that $0 \cdot 1-0 \cdot 15 \mathrm{~mm}-\mathrm{K}^{+}$is sufficient to support sperm : egg fusion, but concentrations $>0.15 \mathrm{~mm}$ are required for penetration of cumulus-intact eggs. When medium of normal osmolality ( $318 \mathrm{mosmol})$ but elevated $\mathrm{K}^{+} / \mathrm{Na}^{+}$ratio $(27.7 \mathrm{mM} / 125 \mathrm{mM})$ was compared with control medium $(2 \cdot 7 / 150)$, the former promoted lower rates of penetration after both 30 and $120 \mathrm{~min}$ preincubation $(8$ and $10 \%$, respectively) than those obtained with control medium ( 45 and $95 \%$ ). Upon reduction to the ratio in control media, however, the fertilizing potential of these suspensions was equivalent to control samples: relatively slow and asynchronous penetration after $30 \mathrm{~min}$ preincubation $(50 \%)$ and rapid, synchronous penetration after $120 \mathrm{~min}(92 \%)$. Thus there was no evidence of a shortening of sperm capacitation time, but rather a suppression of fertilizing potential in the presence of elevated $\mathrm{K}^{+}$. Uterine sperm samples recovered shortly after mating gave similar results when tested in these media 30 and $120 \mathrm{~min}$ after release from the male tract. Preincubation of epididymal samples in high $\mathrm{K}^{+}(27.7 \mathrm{mM})$ hyperosmolal media $(368 \mathrm{mosmol})$ for $30 \mathrm{~min}$ significantly shortened sperm capacitation as shown by rapid penetration of intact eggs $(94 \%)$ after reduction in osmolality, but this appeared to be a non-specific effect; high $\mathrm{Na}^{+}(175 \mathrm{~mm})$ hyperosmolal medium had a similar effect $(98 \%$ of eggs fertilized). Acrosome loss and hyperactivated motility were significantly lower in media with very low or very high $\mathrm{K}^{+}$concentrations but, after alteration to control medium values, increased to levels similar to those obtained with control samples. It is proposed that the relatively high $\mathrm{K}^{+}$concentrations found in female tract fluids $(\sim 20-30 \mathrm{~mm})$ may serve to modulate fertilizing potential of spermatozoa in vivo.
\end{abstract}

\section{Introduction}

The ability to achieve fertilization in vitro in several species has stimulated research into specific requirements for sperm capacitation and acrosome loss. Basic systems have now been established with media formulations used extensively for culture of mammalian embryos (e.g. Biggers, Whitten \& Whittingham, 1971; Whittingham, 1971) and interest has focussed on the effects of individual 
constituents on spermatozoa and eggs. For example, $\mathrm{Ca}^{2+}$ is required for: (1) occurrence of the acrosome reaction (dog: Mahi \& Yanagimachi, 1978; guinea-pig: Yanagimachi \& Usui, 1974; hamster: Yanagimachi, 1982; mouse: Fraser, 1982; ram: Shams-Borhan \& Harrison, 1981); (2) development of hyperactivated motility (Yanagimachi \& Usui, 1974; Fraser, 1977; Yanagimachi, 1982); (3) occurrence of sperm :egg fusion (Yanagimachi, 1978, 1982). On the other hand, an elevated concentration of magnesium, the other divalent cation in most media, inhibited the occurrence of the acrosome reaction in guinea pig spermatozoa (Rogers \& Yanagimachi, 1976). The monovalent cation, potassium, is usually present in culture media at concentrations ranging from 2.5 to $5 \mathrm{~mm}$. Rogers, Ueno \& Yanagimachi (1981) reported that potassium at a minimum of 1-2 $\mathrm{mM}$ was required for fertilization in vitro of both zona-free and zona-intact guinea-pig eggs by guinea-pig spermatozoa. However, those same levels of potassium appeared to retard the acrosome reaction, while $\mathrm{K}^{+}$-free medium, which did not support fertilization, did support acrosome loss. Apparently conflicting results have been reported by Mrsny \& Meizel (1981) for hamster spermatozoa: potassium concentrations below $1 \mathrm{~mm}$ promoted no detectable acrosome loss, while 3-24 mM- $\mathrm{K}^{+}$did-a significant increase in the incidence of the acrosome reaction was detected when $\mathrm{K}^{+}$was raised from 3 to $6 \mathrm{mM}$, but the higher concentrations did not cause a further increase.

In several respects, the relative concentrations of the two monovalent cations, $\mathrm{K}^{+}$and $\mathrm{Na}^{+}$, are of even greater interest since the amount of $\mathrm{K}^{+}$detected in epididymal plasma (Jones, 1978), seminal plasma (see Mann \& Lutwak-Mann, 1981) and female tract fluids (mouse $\mathrm{K}^{+}, 25-32 \mathrm{mM}$ : Borland, Hazra, Biggers \& Lechene, 1977; human $\mathrm{K}^{+} ; 21 \mathrm{mM}$ : Borland, Biggers, Lechene \& Taymor, 1980) the usual milieu for capacitation, is considerably higher than that used in culture media. Evaluation of rabbit spermatozoa recovered in isthmic oviductal fluid, which also has a high $\mathrm{K}^{+}$concentration $(30 \mathrm{~mm})$, indicated reduced amplitude of wave patterns, compared with cells assessed in lower $\mathrm{K}^{+}$concentrations (Johnson \& Overstreet, 1982). However, Toyoda \& Chang (1974) reported that rat sperm suspensions preincubated in medium of normal osmolality but with an elevated $\mathrm{K}^{+} / \mathrm{Na}^{+}$ratio exhibited accelerated sperm capacitation as determined by more rapid sperm penetration, compared with the standard medium.

In view of these conflicting reports, the present study was designed to determine whether $\mathrm{K}^{+}$is required for sperm capacitation in the mouse and, if so, at what point in the process. Acrosome loss, hyperactivated motility, which is usually detectable in mouse spermatozoa around the time they become capable of fertilizing eggs (Fraser, 1977), and rate of sperm penetration were all examined. Additionally, the effects of a high $\mathrm{K}^{+} / \mathrm{Na}^{+}$ratio, in media of both normal osmolality and hyperosmolality, on all of the above characteristics were examined.

\section{Materials and Methods}

Media

All media used were based on a modified Tyrode's solution (Fraser \& Drury, 1975) from which pyruvate, lactate and streptomycin were omitted. Additional $\mathrm{NaCl}$ was included to maintain osmolality (calculated to be $318 \mathrm{mosmol}$ ): $124.54 \mathrm{mM}-\mathrm{NaCl}, 25.00 \mathrm{~mm}-\mathrm{NaHCO}_{3}, 2.68 \mathrm{mM}-\mathrm{KCl}$, $0.36 \mathrm{~mm}-\mathrm{NaH}_{2} \mathrm{PO}_{4}, 0.49 \mathrm{mM}-\mathrm{MgCl}_{2}, 5.56 \mathrm{~mm}$-glucose, $1.80 \mathrm{mM}-\mathrm{CaCl}_{2}$ and 100 units sodium penicillin/ml. Various modifications of the basic medium were also used. In some, $\mathrm{KCl}$ was omitted, but because of the minor alteration in osmolality no adjustment in $\mathrm{NaCl}$ was made. This will be referred to as ' $\mathrm{K}^{+}$-free medium', although there were very small traces of $\mathrm{K}^{+}$in the Analargrade reagents used (calculated maximum contamination of $0.03 \mathrm{~mm}$ ). Water used for medium preparation (Flow, Irvine, U.K.) had been purified by reverse osmosis, sterilized by filtration and contained $<0.1$ p.p.m. heavy metals. The amount of $\mathrm{K}^{+}$measured in $\mathrm{K}^{+}$-free medium with a flame photometer (Corning, Stone, Staffs, U.K.) was $0.05 \mathrm{~mm}$, although this reading was at the lower limit of the instrument's sensitivity. Other medium modifications involved variations in $\mathrm{NaCl}$ and 
$\mathrm{KCl}$ concentrations. The basic medium contained $2 \cdot 7 \mathrm{~mm}-\mathrm{K}^{+}$and $150 \mathrm{~mm}-\mathrm{Na}^{+}(\mathrm{NaCl}, \mathrm{NaHCO}$ and $\mathrm{NaH}_{2} \mathrm{PO}_{4}$ ) for a total of $\sim 153 \mathrm{~mm}$. Various combinations of $\mathrm{KCl}$ and $\mathrm{NaCl}$ which maintained this total were examined, e.g. $10 \mathrm{~K}^{+} / 143 \mathrm{Na}^{+}, 15 \mathrm{~K}^{+} / 138 \mathrm{Na}^{+}, 27 \cdot 7 \mathrm{~K}^{+} / 125 \mathrm{Na}^{+}$. Hyperosmolal media (calculated to be $368 \mathrm{mosmol}$ ) were prepared by adding $25 \mathrm{mM}-\mathrm{KCl}$ or $\mathrm{NaCl}$ to the basic medium : $27 \cdot 7 \mathrm{~K}^{+} / 150 \mathrm{Na}^{+}$or $2 \cdot 7 \mathrm{~K}^{+} / 175 \mathrm{Na}^{+}$. Medium of $368 \mathrm{mosmol}$ was also prepared by adding $50 \mathrm{~mm}$-glucose to control medium. In several experiments potassium was introduced to $\mathrm{K}^{+}$-free medium during sperm preincubation; to minimize volume changes, a solution of $20 \times \mathrm{KCl}(54 \mathrm{mM})$ in basic medium was prepared and $25 \mu \mathrm{l}$ were added to $0.5 \mathrm{ml}$ sperm suspension.

All media contained twice-crystallized bovine plasma albumin (Armour, Eastbourne, Sussex, U.K.) at $4 \mathrm{mg} / \mathrm{ml}$. Incubations were carried out at $37^{\circ} \mathrm{C}$ in $30-\mathrm{mm}$ plastic culture dishes (Sterilin, Teddington, Middx, U.K.) in droplets of medium overlaid with sterilized (autoclaved) liquid paraffin (Boots, Nottingham, U.K.). The gas phase used throughout was $5 \% \mathrm{CO}_{2}: 5 \% \mathrm{O}_{2}: 90 \% \mathrm{~N}_{2}$.

\section{Fertilization in vitro}

Epididymal sperm suspensions were prepared using 2 mature ( $>8$ week) outbred TO male mice and each preparation contained spermatozoa from both males. By releasing half the contents of 1 epididymis from each of the 2 males into $0.5 \mathrm{ml}$ medium, a maximum of 4 suspensions could be prepared. Suspensions were preincubated for up to a total of $2 \mathrm{~h}$ and diluted 10 -fold in the appropriate medium to a final concentration of $1-2 \times 10^{6}$ cells $/ \mathrm{ml}$. Eggs were added to a $0 \cdot 3 \mathrm{ml}$ droplet.

Freshly ovulated eggs were obtained from mature ( $>8$ week) TO female mice induced to superovulate by i.p. injections of 7.5 i.u. PMSG (Gestyl: Organon, Morden, Surrey) and, approximately $54 \mathrm{~h}$ later, 5 i.u. hCG (Pregnyl: Organon). When sperm suspensions were tested at intervals during capacitation, hCG was administered asynchronously so that all eggs were recovered $14 \mathrm{~h}$ after hCG. The majority of experiments utilized cumulus cell- and zona-intact eggs, with cumulus clots being released directly from oviducts into sperm suspensions; in a few, the cumulus masses were washed in medium, then added to sperm suspensions. To prepare zona-free eggs for the remaining experiments, cumulus masses were released into hyaluronidase-containing medium (300 units/ml, bovine testes type I; Sigma, London) to remove cumulus cells. Eggs were washed briefly and transferred to pronase-containing medium $(0.04 \%$ dialysed pronase prepared according to Fraser, 1981 ; Koch-Light, Colnbrook, Bucks, U.K.). When zonae were almost totally solubilized $(30-60 \mathrm{sec})$, eggs were removed to enzyme-free medium and zona remnants were teased away. After a further wash, eggs were transferred to sperm suspensions. In Series I and II, all media used for zona removal were $\mathrm{K}^{+}$-free ; in Series III, the control medium, with $2 \cdot 7 \mathrm{mM}-\mathrm{K}^{+}$, was used throughout.

\section{Series I: addition of $\mathrm{K}^{+}$during capacitation}

To determine whether $\mathrm{K}^{+}$is required for capacitation and/or fertilization, 4 sperm suspensions of $0.5 \mathrm{ml}$ each were prepared as above, with a 5 th dish prepared by releasing the contents of the vasa deferentia into $0.3 \mathrm{ml} \mathrm{K}^{+}$-free medium. When diluted, all preparations yielded similar sperm concentrations. Of the first 4 dishes, one contained control medium $\left(2.7 \mathrm{mM}^{-} \mathrm{K}^{+}\right)$and $3 \mathrm{had} \mathrm{K}^{+}$-free medium. To these latter $3, \mathrm{~K}^{+}$was introduced after 60,90 or $120 \mathrm{~min}$ as described above. After a total preincubation of $120 \mathrm{~min}$ ( $+5 \mathrm{~min}$ when $\mathrm{K}^{+}$was added at $120 \mathrm{~min}$ ), suspensions were diluted in $\mathrm{K}^{+}$-containing medium. Potassium was not added to the fifth dish and $\mathrm{K}^{+}$-free medium was used for sperm dilution. Intact eggs were added to all suspensions. In addition, zona-free eggs were tested with control samples ( $\mathrm{K}^{+}$present continuously) as well as those to which $\mathrm{K}^{+}$was added at $120 \mathrm{~min}$ and those maintained continuously in $\mathrm{K}^{+}$-free medium. Three experiments were carried out. The potassium concentration detectable in $\mathrm{K}^{+}$-free medium containing spermatozoa after $120 \mathrm{~min}$ preincubation was approximately $0.95 \mathrm{~mm}$ as determined by flame photometry, while that 
in control medium was $3.3 \mathrm{~mm}$. After dilution, the $\mathrm{K}^{+}$concentration would be reduced to 0.15 and $2.8 \mathrm{~mm}$, respectively.

\section{Series II: washing sperm suspensions in $K^{+}$-free medium}

Sperm suspensions of $1.0 \mathrm{ml}$ each were prepared in $\mathrm{K}^{+}$-containing and $\mathrm{K}^{+}$-free medium and an aliquot of the latter was washed to remove $\mathrm{K}^{+}$of epididymal origin. After $30 \mathrm{~min}$ preincubation to allow sperm dispersal, $0.5 \mathrm{ml}$ was removed from the $\mathrm{K}^{+}$-free sample and $1 \mathrm{ml} \mathrm{K}^{+}$-free medium was added; after gentle mixing, the sample was centrifuged at $800 \mathrm{~g}$ (room temperature) for $5 \mathrm{~min}$. The supernatant was removed, the pellet was gently resuspended in $0.5 \mathrm{ml}$ fresh $\mathrm{K}^{+}$-free medium, the suspension was transferred to a new dish and covered with equilibrated liquid paraffin.

Suspensions were incubated for a further $90 \mathrm{~min}$, then diluted with medium of the same composition as used for preincubation. The potassium concentration in the washed, $\mathrm{K}^{+}$-free sample was approximately $0.25 \mathrm{mM}$, but this would decrease to about $0.07 \mathrm{~mm}$ upon dilution. All 3 suspensions were tested with intact and zona-free eggs in 6 experiments. In 2 of these experiments, cumulus masses were released into $\mathrm{K}^{+}$-free medium and washed extensively before adding to $\mathrm{K}^{+}$free sperm suspensions (washed and unwashed). Finally, to an aliquot of the washed sperm suspension preincubated for a total of $120 \mathrm{~min}$, concentrated $\mathrm{KCl}$-containing medium was added to give a final concentration of $2.7 \mathrm{mM}$; after $5 \mathrm{~min}$, the suspension was diluted and tested for fertilizing ability.

\section{Series III: alterations in the $\mathrm{K}^{+} / \mathrm{Na}^{+}$ratio}

The effect of increasing $\mathrm{K}^{+}$to concentrations found in the mouse oviduct in iso-osmolal and hyperosmolal media was examined. In this series, 3 or 4 of the following medium compositions were examined in the same experiment: $2 \cdot 7 \mathrm{~K}^{+} / 150 \mathrm{Na}^{+}$(control), $27 \cdot 7 \mathrm{~K}^{+} / 125 \mathrm{Na}^{+}$(iso-osmolal), $27.7 \mathrm{~K}^{+} / 150 \mathrm{Na}^{+}$(hyperosmolal), $2 \cdot 7 \mathrm{~K}^{+} / 175 \mathrm{Na}^{+}$(hyperosmolal). Epididymal suspensions were prepared as above and preincubated for $30 \mathrm{~min}$. They were then diluted as follows: (1) $2 \cdot 7 \mathrm{~K}^{+} / 150$ $\mathrm{Na}^{+} \rightarrow$ same; (2) $27 \cdot 7 \mathrm{~K}^{+} / 125 \mathrm{Na}^{+} \rightarrow$ same; (3) $27 \cdot 7 \mathrm{~K}^{+} / 125 \mathrm{Na}^{+} \rightarrow \mathrm{O} \mathrm{K}^{+} / 150 \mathrm{Na}^{+}$for a final ratio of $\sim 2.7 \mathrm{~K}^{+} / 150 \mathrm{Na}^{+}$; (4) $27.7 \mathrm{~K}^{+} / 150 \mathrm{Na}^{+} \rightarrow$ same; (5) $27.7 \mathrm{~K}^{+} / 150 \mathrm{Na}^{+} \rightarrow \mathrm{O} \mathrm{K}^{+} / 150 \mathrm{Na}^{+}$for a final $\sim 2.7 \mathrm{~K}^{+} / 150 \mathrm{Na}^{+}$; (6) $2.7 \mathrm{~K}^{+} / 175 \mathrm{Na}^{+} \rightarrow$ same, (7) $2.7 \mathrm{~K}^{+} / 175 \mathrm{Na}^{+} \rightarrow 2.7 \mathrm{~K}^{+} / 150 \mathrm{Na}^{+} \rightarrow$ for a final $\sim 2.7 \mathrm{~K}^{+} / 150 \mathrm{Na}^{+}$. Intact eggs were added and assessed as below. The original sperm suspensions were incubated for a further $90 \mathrm{~min}$ (120 min total) and aliquants were again diluted as detailed above. Intact eggs were added to all 7 suspensions, while zona-free eggs were added to $2 \cdot 7 \mathrm{~K}^{+} / 150$ $\mathrm{Na}^{+}$(control), $27 \cdot 7 \mathrm{~K}^{+} / 125 \mathrm{Na}^{+}$and $27 \cdot 7 \mathrm{~K}^{+} / 150 \mathrm{Na}^{+}$. Treatments indicated as (1), (2) and (3) were examined in 4 experiments, while (4), (5), (6) and (7) were used in 3 of these same 4.

In a separate set of experiments, the highest concentration of $\mathrm{K}^{+}$in a medium of normal osmolality (318) which would promote fertilization was determined. The concentrations of $\mathrm{KCl}$ examined were $2 \cdot 7,10.0,15.0$ and $27.7 \mathrm{mM}$. Sperm suspensions were all preincubated for $120 \mathrm{~min}$ before dilution in the medium of the same composition and addition of intact eggs. Finally, hyperosmolal medium containing $55.6 \mathrm{~mm}$-glucose was used for sperm preincubation; samples were tested after $30 \mathrm{~min}$, with dilution into hyperosmolal or normal osmolality medium, to determine whether capacitation was accelerated.

\section{Series IV: uterine sperm suspensions}

The effect of elevated $\mathrm{K}^{+}$in iso-osmolal medium on ejaculated mouse spermatozoa was examined using spermatozoa recovered after natural mating. Mature TO females which had ovulated the previous night were selected (Champlin, Dorr \& Gates, 1973) in the morning, caged with mature TO males, and examined for copulation plugs after 20-30 min. Those with plugs were killed within a few minutes and the uterine horns were clamped at the vaginal end and removed. 
The contents of 1 horn were released in $0.5 \mathrm{ml}$ control medium $\left(2.7 \mathrm{~K}^{+} / 150 \mathrm{Na}^{+}\right)$and of the other horn into $0.5 \mathrm{ml}$ medium containing $27.7 \mathrm{~K}^{+} / 125 \mathrm{Na}^{+}$. Aliquots were diluted immediately into medium of the same composition as described above (time after release from the male similar to epididymal suspensions preincubated for $30 \mathrm{~min}$ ) and eggs were added. The remaining suspensions were incubated for a further $90 \mathrm{~min}$, aliquots were diluted and eggs again added. A total of 6 females was used.

\section{Assessments}

Eggs. Eggs were incubated with sperm suspensions for $\sim 65 \mathrm{~min}$ and then transferred to a fresh small droplet of the appropriate medium; 75 min after gamete mixing, eggs in all treatment groups were fixed simultaneously by flooding the droplets with buffered formalin. Eggs were then stained with $0.75 \%$ aceto-orcein (in $45 \%$ acetic acid) and examined for the presence of a fertilizing spermatozoon. The stage of egg activation, from early anaphase to telophase-second polar body, and the stage of sperm head decondensation, from initial to completed, were assessed (see Fraser, 1979, 1982). The proportions of fertilized eggs exhibiting maximal nuclear development for the time interval used, with eggs at telophase-second polar body and sperm heads fully decondensed, was calculated. When zona-free eggs were used, the incidence of polyspermy was also calculated and used to estimate the relative proportion of 'fit' spermatozoa in the populations tested.

Sperm characteristics. Sperm samples were assessed for acrosome loss at the time spermatozoa and eggs were mixed, i.e. after 30 and $120 \mathrm{~min}$ preincubation. Suspensions were enriched for motile cells by filtering through a short $(\sim 12 \mathrm{~mm}$ ) column of $150-200 \mu \mathrm{m}$ glass beads (Sigma, London) in a Pasteur pipette (see Fraser \& Quinn, 1981); the tapered pipette end was plugged with glass wool and columns were equilibrated with the appropriate medium. Filtrates were fixed with small amounts of neutral, phosphate-buffered formalin (4\% formaldehyde). A drop of fixed suspension was mounted under a coverslip, allowed to dehydrate completely and then rehydrated with a minimal volume of formalin. At least 100 cells in each sample were examined under phase-contrast at $\times 100$ magnification, and the proportions of cells with and without acrosomes were calculated. The fluorescent method used previously (Fraser, 1977) on unfixed cells is unsuitable when multiple suspensions must be examined simultaneously.

After the preincubation periods of 30 and $120 \mathrm{~min}$, diluted (non-filtered) samples were assessed for incidence of hyperactivated motility. This pattern of motility develops in mouse spermatozoa around the time they become capable of fertilizing eggs (Fraser, 1977). The proportion of spermatozoa, relative to suspensions preincubated for $120 \mathrm{~min}$ in control medium, exhibiting hyperactivated motility was estimated for each of the medium compositions tested.

\section{Statistical evaluation}

Statistical significance was determined using Cochran's modification of the $\chi^{2}$ test (Snedecor \& Cochran, 1967). This permits comparison within individual experiments and also takes into account variations in egg sample sizes. In this way, each treatment is compared with the control sperm sample prepared from the same males and tested on the same day.

\section{Results}

\section{Series $I$}

When sperm suspensions were preincubated for $120 \mathrm{~min}$ in medium containing $2.7 \mathrm{mM}-\mathrm{K}^{+}$ (control medium), the proportion of intact eggs fertilized was high and the rate of fertilization was rapid, since most penetrated eggs $(92.6 \%)$ had reached maximal stages of nuclear development for the time interval used (Table 1 ). When potassium $\left(2 \cdot 7 \mathrm{mM}^{-\mathrm{K}^{+}}\right)$was introduced to $\mathrm{K}^{+}-$free sperm 
Table 1. The in-vitro fertilizing ability of mouse sperm suspensions to which $\mathrm{K}^{+}$(final concentration of $2.7 \mathrm{mM}$ ) was added at intervals during the $120 \mathrm{~min}$ preincubation period

\begin{tabular}{|c|c|c|c|c|c|c|}
\hline \multicolumn{2}{|c|}{ Sperm preincubation, min } & \multicolumn{2}{|c|}{ Intact eggs } & \multicolumn{3}{|c|}{ Zona-free eggs } \\
\hline $\mathrm{K}^{+}$-free & $2 \cdot 7 \mathrm{mM} \mathrm{K}^{+}$ & $\begin{array}{l}\text { Eggs fertilized, \% } \\
\text { (range) }\end{array}$ & $\begin{array}{l}\text { Maximal nuclear } \\
\text { development } \dagger, \%\end{array}$ & $\begin{array}{l}\text { Eggs fertilized, } \% \\
\text { (range) }\end{array}$ & $\begin{array}{l}\text { Maximal nuclear } \\
\text { development } \dagger, \%\end{array}$ & $\begin{array}{c}\text { Polyspermic } \\
\text { eggs, } \%\end{array}$ \\
\hline 0 & 120 & $\begin{array}{c}68 / 69,98 \cdot 6 \\
(96-100)\end{array}$ & $92 \cdot 6$ & $50 / 50,100$ & 100 & $72 \cdot 0$ \\
\hline 60 & 60 & $\begin{array}{c}58 / 59,98 \cdot 3 \\
(92-100)\end{array}$ & $94 \cdot 8$ & $-\ddagger$ & $-\ddagger$ & $-\ddagger$ \\
\hline 90 & 30 & $\begin{array}{c}64 / 65,98 \cdot 5 \\
(97-100)\end{array}$ & $93 \cdot 8$ & $--\ddagger$ & $-\ddagger$ & $-\ddagger$ \\
\hline 120 & 5 & $\begin{array}{c}67 / 76,88 \cdot 2 \\
(82-100)\end{array}$ & $91 \cdot 0$ & $49 / 49,100$ & 100 & $32 \cdot 7^{*}$ \\
\hline 120 & 0 & $\begin{array}{l}27 / 64,42 \cdot 2^{* * *} \\
(22-64)\end{array}$ & $68 \cdot 2$ & $\begin{array}{c}23 / 39,59 \cdot 0^{* *} \\
(14-100)\end{array}$ & $95 \cdot 7$ & $13 \cdot 0^{*}$ \\
\hline
\end{tabular}

† Eggs at telophase-second polar body and sperm heads fully decondensed.

$\ddagger$ Not determined.

${ }^{*} P<0.05,{ }^{* *} P<0.025,{ }^{* * *} P<0.01$ compared with $120 \mathrm{~min}$ in $\mathrm{K}^{+}$.

suspensions after 60,90 or $120 \mathrm{~min}$ of the $120 \mathrm{~min}$ preincubation period, similar high proportions of eggs were fertilized and rates of sperm penetration were also rapid (no significant differences when compared with $120 \mathrm{~min}$ preincubation in $2.7 \mathrm{mM}-\mathrm{K}^{+}$). Only when eggs were introduced to sperm suspensions preincubated continuously in $\mathrm{K}^{+}$-free medium was there a significantly lower proportion of eggs penetrated $(P<0.01)$ and a correspondingly slower rate of penetration, with only $68.2 \%$ of eggs showing stages of maximal nuclear development.

With zona-free eggs, again no significant differences were observed in the fertilizing ability of sperm suspensions preincubated continuously in the presence of $\mathrm{K}^{+}$and those to which $\mathrm{K}^{+}$was added only $5 \mathrm{~min}$ before addition of eggs (Table 1), although there was a significantly lower $(P<0.05)$ incidence of polyspermy in the latter treatment group. Sperm suspensions exposed continuously to $\mathrm{K}^{+}$-free medium gave significantly lower proportions of fertilized eggs and lower incidences of polyspermy.

When sperm characteristics were examined, the incidence of acrosome loss in samples to which $\mathrm{K}^{+}$was introduced after 90 or 120 min was significantly lower (Table $3, P<0.05$ ), even though the proportion of eggs fertilized and the rate of sperm penetration did not differ significantly from sperm samples for which $\mathrm{K}^{+}$was present continuously. Acrosome loss in $\mathrm{K}^{+}$-free medium was also significantly lower. Assessment of sperm motility patterns indicated that a lower proportion of motile cells exhibited hyperactivated motility when $\mathrm{K}^{+}$-introduction was delayed; in $\mathrm{K}^{+}$-free medium, some hyperactivated motility could be observed in suspensions albeit to a much lower extent than in the control medium. Although motility was often rather erratic and jerky compared with that of controls, the proportion of motile cells was not decreased.

\section{Series II}

When sperm suspensions were released into $\mathrm{K}^{+}$-free medium, washed after 30 min to remove $\mathrm{K}^{+}$of epididymal origin and incubated for a total of $120 \mathrm{~min}$, the fertilizing ability of washed samples was similar to that of unwashed samples with zona-intact eggs (Table 2). When the intact cumulus masses were washed to remove traces of $\mathrm{K}^{+}$before addition to sperm suspensions, the fertilizing ability of both suspensions was abolished, thus indicating a requirement for extracellular $\mathrm{K}^{+}$to support sperm penetration of intact eggs. Preliminary experiments had indicated that washed and unwashed cumulus-intact eggs were readily and rapidly penetrated by control 
Table 2. The in-vitro fertilizing ability of mouse sperm suspensions preincubated for $120 \mathrm{~min}$ in medium containing $2.7 \mathrm{mM}-\mathrm{K}^{+}$or lacking $\mathrm{K}^{+}$

\begin{tabular}{|c|c|c|c|c|c|}
\hline \multirow[b]{2}{*}{$\begin{array}{l}\mathbf{K}^{+} \text {in } \\
\text { medium }\end{array}$} & \multicolumn{2}{|c|}{ Intact eggs } & \multicolumn{3}{|c|}{ Zona-free eggs } \\
\hline & $\begin{array}{c}\text { Eggs fertilized, \% } \\
\text { (range) }\end{array}$ & $\begin{array}{l}\text { Maximal nuclear } \\
\text { development }+, \%\end{array}$ & $\begin{array}{l}\text { Eggs fertilized, \% } \\
\text { (range) }\end{array}$ & $\begin{array}{l}\text { Maximal nuclear } \\
\text { development } \dagger, \%\end{array}$ & $\begin{array}{c}\text { Polyspermic } \\
\text { eggs, } \%\end{array}$ \\
\hline $2.7 \mathrm{mM}$ & $\begin{array}{c}157 / 163,96 \cdot 3 \\
(77-100)\end{array}$ & $94 \cdot 3$ & $97 / 97,100$ & 100 & $46 \cdot 4$ \\
\hline \multirow[t]{2}{*}{0} & $\begin{array}{c}45 / 138,32 \cdot 6 \\
(6-76)\end{array}$ & 57.8 & $\begin{array}{l}72 / 114,63 \cdot 2^{* * *} \\
(21-100)\end{array}$ & 100 & $12.5^{*}$ \\
\hline & $\pm 0 / 66$ & 0 & - & - & - \\
\hline \multirow[t]{2}{*}{0 (washed) } & $\begin{array}{l}67 / 135,49 \cdot 6 \\
(12-90)\end{array}$ & 68.7 & $\begin{array}{c}27 / 120,22 \cdot 5^{* * *} \\
(0-100)\end{array}$ & 100 & $11 \cdot 1^{*}$ \\
\hline & $\mp 0 / 56$ & 0 & - & - & $\ldots$ \\
\hline
\end{tabular}

$\dagger$ Eggs at telophase-second polar body and sperm heads fully decondensed.

$\ddagger$ Washed cumulus masses.

${ }^{*} P<0.05,{ }^{* *} P<0.01,{ }^{* * *} P<0.001$ compared with 120 min in $\mathrm{K}^{+}$.

suspensions (washed, 97.1\% and unwashed, 94.1\% of eggs penetrated). With zona-free eggs, a significantly lower proportion of eggs was fertilized by suspensions preincubated in $\mathrm{K}^{+}$-free medium, whether unwashed $(P<0.01)$ or washed $(P<0.001)$. Furthermore, the proportion of eggs fertilized by unwashed samples was significantly higher than with washed ones $(P<0.01)$. Great variability was observed with washed sperm suspensions; in 4 of the 6 individual experiments, $0 \%$ of eggs were penetrated, $17 \%$ in one and $100 \%$ in the last. When $\mathrm{K}^{+}$was added to washed, $\mathrm{K}^{+}$-free sperm samples, the rate of fertilization did not differ significantly from that observed in the continuous presence of $\mathrm{K}^{+}$(data not tabulated). Thus both washed and unwashed $\mathrm{K}^{+}$-free samples behaved in a similar manner under all test conditions except with zona-free eggs.

The expression of hyperactivated motility was much reduced in all $\mathrm{K}^{+}$-free samples (Table 3 ). In both groups, the proportion of cells that had undergone the acrosome reaction was significantly lower than in control samples $(P<0.05$; Table 3$)$, although no difference was detected between the two $\mathrm{K}^{+}$-free groups.

Table 3. Acrosome loss by mouse spermatozoa when $\mathrm{K}^{+}$(final concentration $2.7 \mathrm{~mm}$ ) was added at intervals during the 120 min preincubation; unwashed and washed suspensions incubated continuously in $\mathrm{K}^{+}$-free medium were also examined

\begin{tabular}{|c|c|c|c|c|}
\hline \multicolumn{2}{|c|}{ Sperm preincubation, min } & \multirow{2}{*}{$\begin{array}{l}\text { Hyperactivated } \\
\text { motility } \dagger\end{array}$} & \multicolumn{2}{|c|}{$\begin{array}{l}\text { Spermatozoa lacking acrosome } \\
(\text { mean } \pm \text { s.e.m.) }\end{array}$} \\
\hline $\mathrm{K}^{+}$-free & $2 \cdot 7 \mathrm{mM} \mathrm{K}^{+}$ & & Series I & Series II \\
\hline 0 & 120 & +++ & $29 \cdot 3 \pm 2 \cdot 2$ & $26.8 \pm 2.7$ \\
\hline 60 & 60 & $++-++t$ & $23.7 \pm 2.9$ & - \\
\hline 90 & 30 & ++ & $15 \cdot 3 \pm 6 \cdot 1^{*}$ & - \\
\hline 120 & 5 & ++ & $15 \cdot 3 \pm 5 \cdot 1^{*}$ & - \\
\hline 120 & 0 & \pm-+ & $17.0 \pm 3.6^{*}$ & $15 \cdot 0 \pm 2 \cdot 9^{*}$ \\
\hline 120 & $0 \ddagger$ & \pm-+ & - & $15 \cdot 5 \pm 3 \cdot 1^{*}$ \\
\hline
\end{tabular}

$\dagger$ Relative to samples in $2.7 \mathrm{mM}-\mathrm{K}^{+}$for $120 \mathrm{~min}(+++)$; assessed at $120 \mathrm{~min}$.

$\ddagger$ Suspensions washed after $30 \mathrm{~min}$ and resuspended in $\mathrm{K}^{+}$-free medium.

${ }^{*} P<0.05$ compared with $120 \mathrm{~min}$ in $\mathrm{K}^{+}$. 


\section{Series $I I I$}

These treatments were examined in the same series of experiments, so that within- and between-experiment comparisons are possible. Some media tested were of normal osmolality but altered $\mathrm{K}^{+} / \mathrm{Na}^{+}$ratios, while others had altered ratios and were hyperosmolal. When sperm suspensions were preincubated in control medium $\left(2 \cdot 7 \mathrm{~K}^{+} / 150 \mathrm{Na}^{+}\right)$and tested for fertilizing ability in vitro after 30 and 120 min preincubation with intact eggs, results were similar to those obtained in earlier studies (Fraser, 1979, 1981, 1982). Great variability amongst individual experiments in the total proportion of eggs fertilized and asynchronous sperm penetration were observed when samples were preincubated for only $30 \mathrm{~min}$ (Table 4). In marked contrast, the same suspensions preincubated for $120 \mathrm{~min}$ provided consistently high proportions of fertilized eggs and synchronous penetration of fertilizing spermatozoa (Table 4). When spermatozoa from the same males were released into iso-osmolal medium with a high $\mathrm{K}^{+} / \mathrm{Na}^{+}$ratio (i.e. $27 \cdot 7 / 125$ ), suspensions preincubated for $30 \mathrm{~min}$ and $120 \mathrm{~min}$ were able to promote only very low levels of fertilization with intact eggs compared with the control medium. However, when these suspensions were diluted at $30 \mathrm{~min}$ and $120 \mathrm{~min}$ to alter the ionic composition essentially to that of control medium, their fertilizing ability was almost identical to that of control suspensions, i.e. relatively poor asynchronous fertilization after $30 \mathrm{~min}$ and very good synchronous fertilization after $120 \mathrm{~min}$ preincubation (Table 4). Spermatozoa were therefore relatively infertile in the continuous presence of $27.7 \mathrm{~K}^{+} / 125 \mathrm{Na}^{+}$but, once transferred to the control medium with $2.7 \mathrm{~K}^{+} / 150 \mathrm{Na}^{+}$, they exhibited fertilizing potential similar to those maintained continuously in control medium. There was no shortening of capacitation time.

Table 4. The effect of modifications in the $\mathrm{K}^{+} / \mathrm{Na}^{+}$ratio, maintaining normal total osmolality, on mouse sperm fertilizing ability in vitro

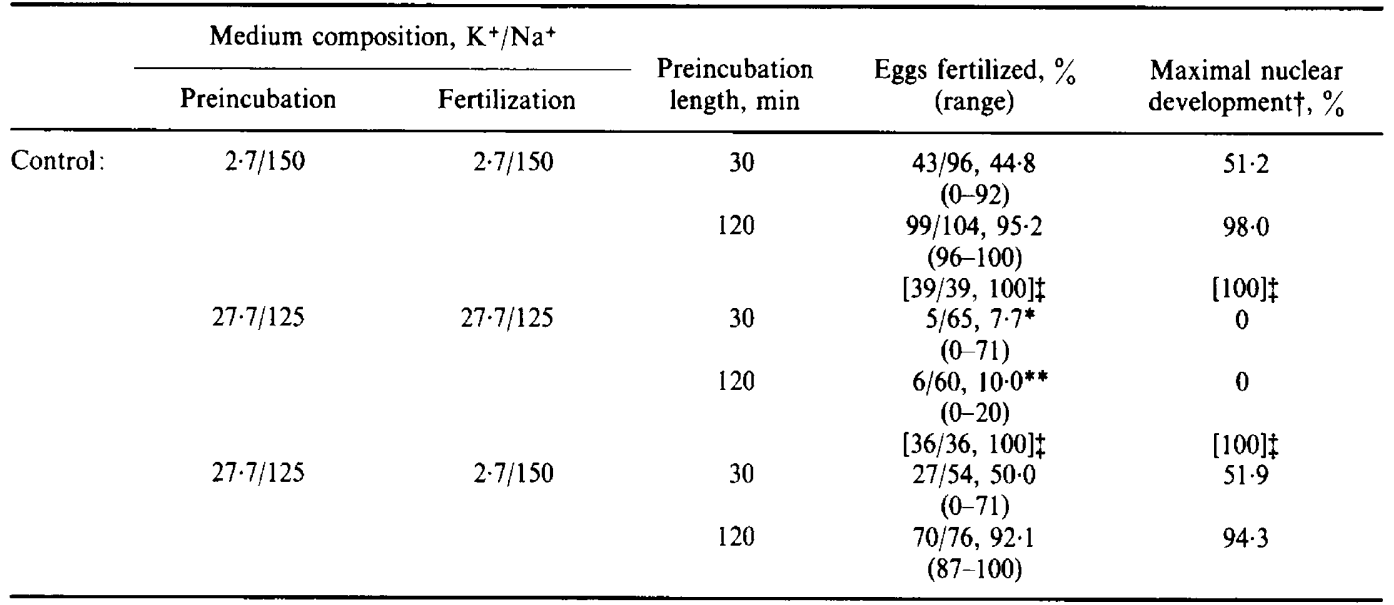

† Eggs at telophase-second polar body and sperm heads fully decondensed.

$\ddagger$ Values for zona-free eggs.

* $P<0.05,{ }^{* *} P<0.01$ compared with appropriate control group.

When sperm suspensions were prepared in hyperosmolal medium, whether with elevated $\mathrm{K}^{+}$ $\left(27.7 \mathrm{~K}^{+} / 150 \mathrm{Na}^{+}\right)$or elevated $\mathrm{Na}^{+}\left(2 \cdot 7 \mathrm{~K}^{+} / 175 \mathrm{Na}^{+}\right)$, low levels of fertilization of intact eggs were observed at 30 and $120 \mathrm{~min}$ (Table 5). However, when the medium composition was adjusted to $\sim 2.7 \mathrm{~K}^{+} / 150 \mathrm{Na}^{+}$after a 30 -min preincubation, $>90 \%$ of eggs were fertilized and, even after $120 \mathrm{~min}$, these sperm suspensions retained the ability to fertilize the great majority of eggs in a synchronous manner (Table 5). Thus the exposure to hyperosmolal media with increased 
Table 5. The effect of modifications in the $\mathrm{K}^{+} / \mathrm{Na}^{+}$ratio which increased the concentration of $\mathrm{K}^{+}$or $\mathrm{Na}^{+}$ by $25 \mathrm{~mm}$ and the total osmolality to 50 mosmol above the control level

\begin{tabular}{|c|c|c|c|c|c|}
\hline & \multicolumn{2}{|c|}{ Medium composition, $\mathrm{K}^{+} / \mathrm{Na}^{+}$} & \multirow{2}{*}{$\begin{array}{l}\text { Preincubation } \\
\text { length, min }\end{array}$} & \multirow{2}{*}{$\begin{array}{l}\text { Eggs fertilized, } \% \\
\text { (range) }\end{array}$} & \multirow{2}{*}{$\begin{array}{l}\text { Maximal nuclear } \\
\text { development } \dagger, \%\end{array}$} \\
\hline & Preincubation & Fertilization & & & \\
\hline \multirow[t]{11}{*}{$\$$ Control: } & $2 \cdot 7 / 150$ & $2 \cdot 7 / 150$ & 30 & $\begin{array}{c}43 / 96,44 \cdot 8 \\
(0-92)\end{array}$ & $51 \cdot 2$ \\
\hline & & & 120 & $\begin{array}{c}99 / 104,95 \cdot 2 \\
(96-100)\end{array}$ & 98.0 \\
\hline & $27 \cdot 7 / 150$ & $27 \cdot 7 / 150$ & 30 & $\begin{array}{c}2 / 24,8 \cdot 3^{*} \\
(0-25)\end{array}$ & 0 \\
\hline & & & 120 & $\begin{array}{l}1 / 29,3 \cdot 4^{* *} \\
(0-8)\end{array}$ & 0 \\
\hline & & & & {$[41 / 41,100] \S$} & {$[100] \S$} \\
\hline & $27 \cdot 7 / 150$ & $2 \cdot 7 / 150$ & 30 & $\begin{array}{c}29 / 31,93 \cdot 5^{*} \\
(83-100)\end{array}$ & $65 \cdot 5^{\circ}$ \\
\hline & & & 120 & $\begin{array}{c}34 / 53,64 \cdot 3^{*} \\
(44-85)\end{array}$ & $82 \cdot 4$ \\
\hline & $2 \cdot 7 / 175$ & $2 \cdot 7 / 175$ & 30 & $\begin{array}{l}1 / 31,3 \cdot 2^{*} \\
(0-9)\end{array}$ & 0 \\
\hline & & & 120 & $\begin{array}{c}8 / 34,23 \cdot 5^{* *} \\
(17-50)\end{array}$ & $50 \cdot 0$ \\
\hline & $2 \cdot 7 / 175$ & $2 \cdot 7 / 150$ & 30 & $\begin{array}{c}49 / 50,98 \cdot 0^{*} \\
(96-100)\end{array}$ & $83 \cdot 7$ \\
\hline & & & 120 & $\begin{array}{c}59 / 72,81 \cdot 9 \\
(55-95)\end{array}$ & $96 \cdot 6$ \\
\hline
\end{tabular}

$\dagger$ Eggs at telophase-second polar body and sperm heads fully decondensed.

† Same data as shown in Table 4.

$\S$ Values for zona-free eggs.

${ }^{*} P<0.05,{ }^{* *} P<0.01$ compared with appropriate control group.

ionic concentrations appeared to shorten capacitation time significantly. Hyperosmolal medium prepared by addition of $50 \mathrm{~mm}$-glucose to the control medium did not shorten capacitation time: after $30 \mathrm{~min}$ preincubation in control and $55 \mathrm{~mm}$-glucose (hyperosmolal) media the proportion of eggs fertilized was $10 / 20(50 \%)$ and $2 / 24(8.3 \%)$ respectively. When the hyperosmolal medium was diluted to give normal osmolality, $16 / 40(40 \%)$ eggs were fertilized.

Little difference in the ability to fertilize zona-free eggs could be detected among suspensions preincubated for 120 min and diluted in medium containing $2.7 \mathrm{~K}^{+} / 150 \mathrm{Na}^{+}$(control medium), $27.7 \mathrm{~K}^{+} / 125 \mathrm{Na}^{+}$or $27.7 \mathrm{~K}^{+} / 150 \mathrm{Na}^{+}$. In all 3 media, $100 \%$ of eggs were fertilized and all had reached maximal stages of nuclear development (Tables $4 \& 5$ ); there was, however, a significantly lower $(P<0.05)$ incidence of polyspermy in the presence of $27.7 \mathrm{~K}^{+} / 125 \mathrm{Na}^{+}(41.7 \%)$ compared with control medium $(89.7 \%)$; the value for high $\mathrm{K}^{+}$hyperosmolal medium was $65.9 \%$.

Acrosome loss in the suspensions varied considerably, depending on length of preincubation and medium composition. After $30 \mathrm{~min}$ in most media, acrosome loss was low $(<10 \%)$, but in hyperosmolal $2.7 \mathrm{~K}^{+} / 175 \mathrm{Na}^{+}$, a significantly higher $(P<0.01)$ proportion of spermatozoa had lost acrosomes, compared with control samples. No such precocious loss was detected in $27 \cdot 7 \mathrm{~K}^{+} / 150$ $\mathrm{Na}^{+}$, although dilution into $\mathrm{K}^{+}$-free medium precipitated high levels of acrosome loss (data not tabulated). After 120 min preincubation, acrosome loss was still low in the presence of $27.7 \mathrm{~K}^{+} / 125$ $\mathrm{Na}^{+}$, but within $5 \mathrm{~min}$ of shifting to $2 \cdot 7 \mathrm{~K}^{+} / 150 \mathrm{Na}^{+}$, significant acrosome loss occurred and the figure did not differ significantly from that obtained for samples incubated continuously in $2.7 \mathrm{~K}^{+} /$ $150 \mathrm{Na}^{+}$. In hyperosmolal media obtained by altering $\mathrm{K}^{+}$and $\mathrm{Na}^{+}$, acrosome loss after 120 min was significantly higher than observed in control samples. Motility was also affected by medium composition; in all media examined, sperm motility was less vigorous and rather more erratic than in control medium although similar proportions of cells were motile. The expression of 
hyperactivated motility after $120 \mathrm{~min}$ was lower in test media, although it could be detected in all samples. Upon dilution into media which provided a $\mathrm{K}^{+} / \mathrm{Na}^{+}$ratio of $2 \cdot 7 / 150$, however, all samples exhibited hyperativated motility equivalent to control samples. Hyperactivated motility could be detected in the diluted, originally hyperosmolal, samples with altered $\mathrm{K}^{+} / \mathrm{Na}^{+}$after only 30 min (rating of ++ , compared with \pm at $30 \mathrm{~min}$ and +++ at $120 \mathrm{~min}$ for control samples). This feature correlated well with the high fertilizing ability of these samples (Table 5).

In the ancillary study to determine the maximum $\mathrm{K}^{+}$concentration to support fertilization and acrosome loss, it was evident that above $10 \mathrm{~mm}-\mathrm{K}^{+} / 143 \mathrm{~mm}-\mathrm{Na}^{+}$spermatozoa were inhibited to the same extent as observed with $27.7 \mathrm{~K}^{+} / 125 \mathrm{Na}^{+}$and these data are not tabulated. Although fertilization was not reduced in the presence of $10 \mathrm{mM}-\mathrm{K}^{+}(54 / 64,84.4 \%$ compared with $79 / 88$, $89.8 \%$ for $2.7 \mathrm{~mm}-\mathrm{K}^{+}$in control medium), hyperactivated motility was reduced $(+$to ++$)$. No significant alterations in the proportion of spermatozoa undergoing the acrosome reaction were observed (Table 6).

Table 6. Acrosome loss by mouse spermatozoa preincubated 30 and $120 \mathrm{~min}$ in vitro in media with modifications in the $\mathrm{K}^{+} / \mathrm{Na}^{+}$ratio

\begin{tabular}{lcccc} 
& & \multicolumn{2}{c}{ Spermatozoa lacking acrosome (mean \pm s.e.m.) } \\
\cline { 3 - 4 } \multicolumn{2}{c}{ Medium composition, $\mathrm{K}^{+} / \mathrm{Na}^{+}$} & $\begin{array}{c}\text { Hyperactivated } \\
\text { motility }\end{array}$ & 30 min preincubation & 120 min preincubation \\
\hline Control: & $2 \cdot 7 / 150$ & +++ & $8 \cdot 0 \pm 2 \cdot 8$ & $24 \cdot 6 \pm 2 \cdot 1$ \\
& $10 / 143$ & +-++ & - & $16 \cdot 0 \pm 2 \cdot 8$ \\
$27 \cdot 7 / 125$ & + & $3 \cdot 0 \pm 1 \cdot 2$ & $10 \cdot 5 \pm 2 \cdot 0^{* *}$ \\
$27 \cdot 7 / 125 \rightarrow 2 \cdot 7 / 150 \pm$ & +++ & $8 \cdot 3 \pm 3 \cdot 0$ & $31 \cdot 3 \pm 6 \cdot 3$ \\
$27 \cdot 7 / 150$ & +-++ & $4 \cdot 8 \pm 1 \cdot 9$ & $47 \cdot 0 \pm 2 \cdot 8^{*}$ \\
$2 \cdot 7 / 175$ & +-++ & $46 \cdot 7 \pm 4 \cdot 4^{* *}$ & $54 \cdot 5 \pm 3 \cdot 3^{* * *}$ \\
\hline
\end{tabular}

$\dagger$ Relative to samples in $2.7 \mathrm{~K}^{+} / 150 \mathrm{Na}^{+}(+++)$for $120 \mathrm{~min}$; assessed at $120 \mathrm{~min}$.

$\ddagger$ Suspensions were diluted $1: 9$ in $\mathrm{K}^{+}$-free medium immediately before assessment to yield $\sim 2 \cdot 7 \mathrm{~K}^{+} / 150 \mathrm{Na}^{+}$.

${ }^{*} P<0.05,{ }^{* *} P<0.01$ compared with appropriate control group.

\section{Series IV}

When uterine spermatozoa were released into control medium shortly after mating and tested for fertilizing ability, results were very similar to those obtained with epididymal spermatozoa (Table 7): great variability among experiments in the proportion of eggs fertilized and a minority of these at maximal stages of nuclear development. After a further $90 \mathrm{~min}$, however, the response in

Table 7. The in-vitro fertilizing ability of mouse uterine spermatozoa recovered within 30 min of mating

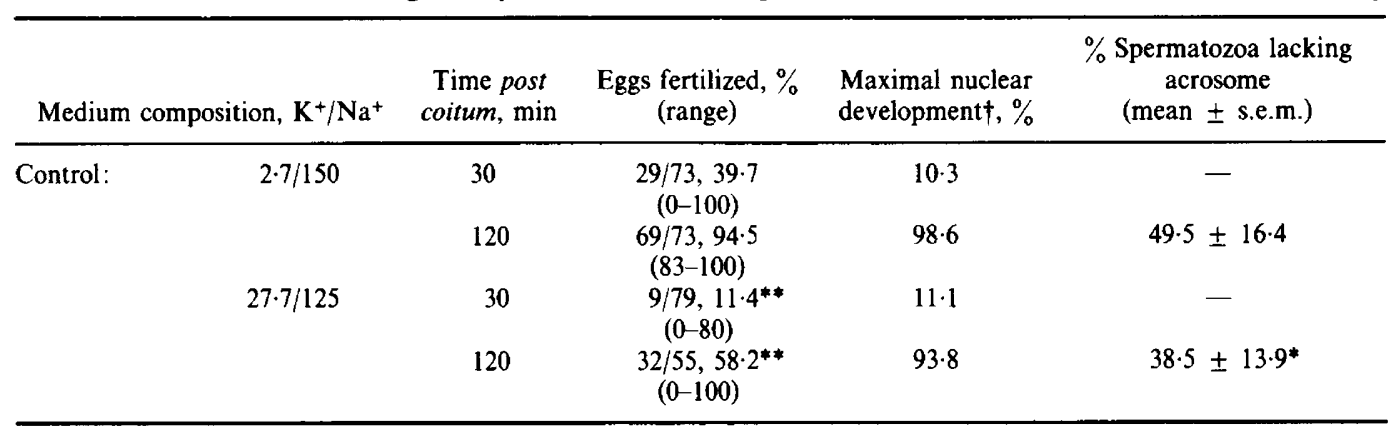

† Eggs at telophase-second polar body and sperm heads fully decondensed.

${ }^{*} P<0.05,{ }^{* *} P<0.025$ compared with appropriate control groups. 
both categories was $>90 \%$. When spermatozoa from the same females were released into medium containing $27.7 \mathrm{~K}^{+} / 125 \mathrm{Na}^{+}$, the proportion of eggs fertilized at both assessment times was significantly lower $(P<0.05)$ than the corresponding figure obtained in control medium. There was also a significantly lower $(P<0.05)$ incidence of acrosome loss after $120 \mathrm{~min}$ in $27.7 \mathrm{~K}^{+} / 125$ $\mathrm{Na}^{+}$, but the inter-experiment variability was quite high. This may reflect a slight increase in viscosity of some samples at the time of release due to a carry-over of seminal plasma constituents which subsequently affected the filtration process. Hyperactivated motility was slightly reduced in the presence of elevated $\mathrm{K}^{+}$.

\section{Discussion}

Extracellular $\mathrm{K}^{+}$is required for successful fertilization of cumulus- and zona-intact mouse eggs. Whether free of epididymally-derived $\mathrm{K}^{+}$or not during the 2-h preincubation period, sperm suspensions in $\mathrm{K}^{+}$-free medium were unable to fertilize eggs in washed cumulus masses. The fact that those same suspensions were able to fertilize some eggs present in unwashed cumulus masses suggests that $\mathrm{K}^{+}$contributed by oviductal fluid, released along with eggs, was sufficient to promote a low degree of fertilization. In contrast, some penetration of zona-free eggs was always obtained with unwashed suspensions while negligible rates were generally obtained with washed, $\mathrm{K}^{+}$-free suspensions (Table 2). Based on measured $\mathrm{K}^{+}$concentrations in preincubated washed and unwashed suspensions which were then reduced by dilution with $\mathrm{K}^{+}$-free medium, the minimum $\mathrm{K}^{+}$concentration required for penetration of intact eggs is $>0.15 \mathrm{mM}$, while that required for fusion with zona-free eggs is approximately $0 \cdot 1-0 \cdot 15 \mathrm{~mm}$.

Temporally, extracellular $\mathrm{K}^{+}$is only required at the very end of sperm capacitation since a 5min exposure to $\mathrm{K}^{+}$after a $2-\mathrm{h}$ preincubation in $\mathrm{K}^{+}$-free medium promoted rapid, synchronous sperm penetration of intact eggs. These results represent the fertilizing ability of the sperm population as a whole, i.e. there were sufficient numbers of 'fit' spermatozoa to ensure fertilization of most eggs. The fact that these same suspensions achieved a significantly lower incidence of polyspermy with zona-free eggs, compared with control samples, suggests that the total number of 'fit' cells was lower in suspensions deprived of $\mathrm{K}^{+}$for much of the capacitation period. Since all penetrated zona-free eggs showed maximal stages of nuclear development, however, individual spermatozoa appeared to respond to $\mathrm{K}^{+}$introduction in an 'all or none' fashion; if this were not so, then a retardation in fusion might have been expected.

Acrosome loss and hyperactivated motility were significantly reduced in $\mathrm{K}^{+}$-free suspensions and in those to which $\mathrm{K}^{+}$was introduced after 90 and $120 \mathrm{~min}$, despite the high levels of fertilization obtained with the last 2 treatments. Since acrosome loss was similarly low in all 3 groups, the qualitative effect on motility may have been the primary defect preventing fertilization of washed intact eggs and reducing fertilization of zona-free eggs. Indeed, the most striking effect of a 5 -min exposure to $\mathrm{K}^{+}$was the marked increase in hyperactivated motility (Table 3 ). Even if acrosome loss is high, poor motility may result in low penetration rates of zona-free eggs (Fraser, 1981).

In a similar study utilizing guinea-pig spermatozoa, Rogers et al. (1981) reported that a minimum of 1-2 mM-K $\mathrm{K}^{+}$was required for successful fertilization of both intact and zona-free guinea-pig eggs. Unlike guinea-pig spermatozoa, there was no suggestion that $\mathrm{K}^{+}$at a concentration promoting fertilization retarded the mouse sperm acrosome reaction. Rather, as observed with the hamster (Mrsny \& Meizel, 1981), very low levels of $\mathrm{K}^{+}$promoted a lower incidence of acrosome loss than did higher concentrations.

It is unlikely that spermatozoa in vivo will ever be faced with $\mathrm{K}^{+}$-free conditions. Reproductive tract fluids, both male and female, tend to have high concentrations of $\mathrm{K}^{+}$, compared with normal serum values (see 'Introduction'). In medium with a $\mathrm{K}^{+} / \mathrm{Na}^{+}$composition resembling that found in the female mouse oviduct around the time of fertilization (Borland et al., 1977), i.e. iso-osmolal high 
$\mathrm{K}^{+}\left(27 \cdot 7 \mathrm{~K}^{+} / 125 \mathrm{Na}^{+}\right)$, both the acrosome reaction and hyperactivated motility were much reduced after 120 min preincubation compared with control samples. The fertilizing ability of these suspensions with intact eggs after 30 and 120 min preincubation was significantly lower than that of comparable control suspensions, even though penetration of zona-free eggs was not inhibited. However, by adjusting the final $\mathrm{K}^{+} / \mathrm{Na}^{+}$ratio to that of control medium $\left(2.7 \mathrm{~K}^{+} / 150 \mathrm{Na}^{+}\right)$just before assessment, these same suspensions became essentially indistinguishable from controls (Tables $4 \& 6$ ). After 30 min preincubation, the proportion of intact eggs penetrated was highly variable and asynchronous penetration was evident, while rapid and synchronous penetration of most eggs was obtained after $120 \mathrm{~min}$. Rates of acrosome loss after $30 \mathrm{~min}$ were low $(<10 \%)$ but increased to $25-30 \%$ after $120 \mathrm{~min}$, and hyperactivated motility was evident after $120 \mathrm{~min}$. Thus iso-osmolal medium with a high $\mathrm{K}^{+} / \mathrm{Na}^{+}$ratio permitted sperm capacitation to proceed at the usual rate but interfered with expression of functional ability. Capacitation was not accelerated, a finding at variance with the study of Toyoda \& Chang (1974) on the rat. On the basis of Niwa \& Chang's (1974) demonstration that successful fertilization was greatly dependent on rat sperm concentration during preincubation, it is likely that the high $\mathrm{K}^{+}$medium of Toyoda \& Chang (1974) merely maintained viability of the relatively dense sperm suspensions, perhaps by decreasing their metabolic rate. Pholpramool \& Chaturapanich (1979) have reported that progressive motility of rat spermatozoa was significantly reduced in media with a high $\mathrm{K}^{+} / \mathrm{Na}^{+}$ratio. Lowering the $\mathrm{K}^{+}$ concentration would then permit cells to demonstrate their fertilizing potential. Such an interpretation of Toyoda \& Chang's (1974) results would be consistent with the results in the present study.

Because it is difficult to obtain ejaculated semen samples from small laboratory animals, almost all in-vitro fertilization experiments utilize epididymal sperm samples. Seminal plasma and uterine fluid (Borland et al., 1977), as well as epididymal plasma (Jones, 1978), have elevated $\mathrm{K}^{+}$levels but differ in overall composition. For this reason, ejaculated, uterine spermatozoa were recovered shortly after mating to permit comparisons with epididymal spermatozoa. Uterine samples released into control medium exhibited changes in fertilizing ability very similar to those of epididymal samples, i.e. $30 \mathrm{~min}$ after release from the male penetration rates were slow and asynchronous, while after $120 \mathrm{~min}$ penetration was rapid and synchronous. Exposure to seminal plasma and uterine fluid did not significantly alter functional ability, and motility patterns correlated well with fertility, i.e. expression of hyperactivated motility within 120 min of release. Uterine sperm samples released into and tested in iso-osmolal medium with a $27.7 \mathrm{~K}^{+} / 125 \mathrm{Na}^{+}$ ratio, like their epididymal counterparts, were less fertile than samples maintained in control medium (Table 7). Nevertheless, uterine samples tested after $120 \mathrm{~min}$ appeared to be more fertile than epididymal samples (58\% and $10 \%$ of eggs fertilized, respectively; Tables $4 \& 7)$, and although variations amongst males must be allowed for, $90 \%$ of these eggs penetrated by uterine suspensions in $27.7 \mathrm{~K}^{+} / 125 \mathrm{Na}^{+}$were at maximal stages of nuclear development compared with $0 \%$ for those in the equivalent epididymal group. Neither acrosome loss nor motility in uterine samples were reduced to the same extent as epididymal ones, perhaps accounting for these differences. Constituents of seminal plasma and/or uterine fluid appear capable of modifying the response of epididymal spermatozoa to a shift in the $\mathrm{K}^{+} / \mathrm{Na}^{+}$ratio.

When hyperosmolal media (elevated $\mathrm{K}^{+}$or $\mathrm{Na}^{+}$concentrations) were used for preincubation and fertilization, very low rates of fertilization were obtained with intact eggs (Table 5). However, transfer of these suspensions after a 30-min preincubation to medium with control levels of $\mathrm{K}^{+}$and $\mathrm{Na}^{+}$indicated that capacitation time had been significantly decreased as evidenced by rapid and synchronous penetration of the majority of eggs (Table 5), unlike control suspensions. Even after a 2-h preincubation in hyperosmolal media, spermatozoa were highly fertile when osmolality was reduced. Hyperosmolal media with elevated $\mathrm{K}^{+}$or $\mathrm{Na}^{+}$had similar effects on fertilizing ability and motility, but different ones on acrosome loss. After $30 \mathrm{~min}$ acrosome loss was high $(47 \%)$ in high $\mathrm{Na}^{+}$medium but very low in the presence of high $\mathrm{K}^{+}(5 \%$, similar to control values), although the incidence in the latter group increased when $\mathrm{K}^{+}$was reduced to $2.7 \mathrm{mM}$; after $120 \mathrm{~min}$, acrosome 
loss was high in both media. Hyperactivated motility was inhibited in both hyperosmolal media, but the change to iso-osmolal conditions precipitated this specific motility pattern, irrespective of preincubation time, and indicated the promotion of precocious expression of hyperactivated motility. Brackett \& Oliphant (1975) reported alteration in the pattern of motility exhibited by rabbit spermatozoa after similar treatment. The observation in this study that high ionic strength treatment shortens capacitation time, i.e. supports the same incidence of fertilization as control conditions but more rapidly, confirms the report of Niwa \& Chang (1975) on rat spermatozoa. In another study in which poor capacitation of mouse sperm suspensions was obtained under control conditions, a high salt treatment promoted higher cleavage rates (Oliphant \& Brackett, 1973). The latter workers also observed that an ionic increase in osmolality was required to obtain an effect, and the present study confirms this.

It has been suggested that high ionic strength media cause loss of sperm surface components, such as decapacitation factors, leading to destabilization of the sperm membranes and ultimately to the acrosome reaction (Oliphant \& Brackett, 1973; Brackett \& Oliphant, 1975; O'Rand, 1979). The present results, demonstrating a marked acceleration in the ability of treated cells to undergo the acrosome reaction compared with control samples from the same males, are consistent with such an hypothesis.

It is evident that the absolute concentration of extracellular potassium ions in iso-osmolal media, while not affecting capacitation per se, can significantly modulate mouse sperm motility, acrosome loss and fertilizing ability. These effects might be mediated via glycolysis, particularly since $\mathrm{K}^{+}$appears to be required for maximal activity of at least one enzyme in the glycolytic pathway, namely phosphofructokinase (Paetkau \& Lardy, 1967). Reductions in sperm glycolysis in media both lacking and containing high concentrations of $\mathrm{K}^{+}(15 \mathrm{~mm})$, compared with those containing moderate amounts (5-6 mM), have been reported (man: Peterson \& Freund, 1973; ram: Murdoch \& White, 1971), although very high $\mathrm{K}^{+}$concentrations (>100 mM) appear to stimulate metabolic activity in bull (Babcock, Rufo \& Lardy, 1983) and human (Peterson \& Freund, 1973) spermatozoa. Peterson \& Freund suggested that interactions between the glycolytic pathway and a membrane $\mathrm{Na}^{+}-\mathrm{K}^{+}$ATPase were involved, and Mrsny \& Meizel (1981) have reported that this enzyme activity is required to support the acrosome reaction in hamster spermatozoa. Fraser $\&$ Quinn (1981) have demonstrated that glycolytic metabolism is required for successful fertilization by mouse spermatozoa, not for capacitation but for the terminal events of acrosome loss and hyperactivated motility. The addition of glucose to suspensions after $120 \mathrm{~min}$ preincubation in substrate-free medium was sufficient to promote rapid, synchronous penetration of intact mouse eggs. The similarity in functional pattern between this and those obtained with very low and very high $\mathrm{K}^{+}$levels is consistent with a $\mathrm{K}^{+}$effect mediated via glycolysis. Whether the hyperosmolal media also affect glycolysis in a similar manner is unclear and it is evident that other responses are also evoked in the spermatozoa since capacitation is significantly shortened.

The reduction in motility observed in this study in vitro, as well as in rabbit spermatozoa obtained in oviducal fluid (Overstreet, Katz \& Johnson, 1980) which has a high $\mathrm{K}^{+}$concentration (Johnson \& Overstreet, 1982), may represent a mechanism for regulating sperm-depending progress within the female tract to ensure an adequate population of potentially fertilizing spermatozoa when eggs enter the ampulla. In many animals, the arrival of spermatozoa in the isthmic portion of the oviduct is followed by slow transport to the ampulla for fertilization (Harper, 1973; Overstreet, Cooper \& Katz, 1978; Cummins \& Yanagimachi, 1982), and the arrival of motile spermatozoa in the ampulla often coincides with ovulation (hamster: Cummins \& Yanagimachi, 1982; rabbit: Harper, 1973; Overstreet \& Cooper, 1979). Unlike the values reported for the oviduct, the $\mathrm{K}^{+}$concentration of follicular fluid from several species (e.g. cow and human: Edwards, 1974) and murine bursal sac fluid, which presumably reflects the composition of follicular fluid associated with recently ovulated eggs, is moderate and similar to serum values $(\sim 5-$ $7 \mathrm{mM}$ ). It is proposed that after ovulation the immediate microenvironment of eggs in vivo has a sufficiently low $\mathrm{K}^{+}$concentration that sperm motility is increased with a concomitant expression of 
hyperactivated motility and, given the appropriate stimulus, the acrosome reaction occurs, thus ensuring successful fertilization even with very low sperm :egg ratios.

\section{This work was supported in part by a grant from the Agricultural Research Council.}

\section{References}

Babcock, D.F., Rufo, G.A. \& Lardy, H.A. (1983) Potassium-dependent increases in cytosolic $\mathrm{pH}$ stimulate metabolism and motility of mammalian sperm. Proc. natn. Acad. Sci. U.S.A. 80, 1327-1331.

Biggers, J.D., Whitten, W.K. \& Whittingham, D.G. (1971) The culture of mouse embryos in vitro. In Methods in Mammalian Embryology, pp. 86-116. Ed. J. C. Daniel, Jr. W. H. Freeman, San Francisco.

Borland, R.M., Hazra, S., Biggers, J.D. \& Lechene, C.P. (1977) The elemental composition of the environments of the gametes and preimplantation embryo during initiation of pregnancy. Biol. Reprod. 16, 147157.

Borland, R.M., Biggers, J.D., Lechene, C.P. \& Taymor, M.L. (1980) Elemental composition of fluid in the human Fallopian tube. J. Reprod. Fert. 58, 479-482.

Brackett, B.G. \& Oliphant, G. (1975) Capacitation of rabbit spermatozoa in vitro. Biol. Reprod. 12, 260-274.

Champlin, A.K., Dorr, D.L. \& Gates, A.H. (1973) Determining the stage of the estrous cycle in the mouse by the appearance of the vagina. Biol. Reprod. 8, 491-494.

Cummins, J.M. \& Yanagimachi, R. (1982) Sperm-egg ratios and the site of the acrosome reaction during in vivo fertilization in the hamster. Gamete Res. 5, 239256.

Edwards, R.G. (1974) Follicular fluid. J. Reprod. Fert. 37, 189-219.

Fraser, L.R. (1977) Motility patterns in mouse spermatozoa before and after capacitation. J. exp. Zool. 202, 439-444.

Fraser, L.R. (1979) Accelerated mouse sperm penetration in vitro in the presence of caffeine. J. Reprod. Fert. 57, 377-384.

Fraser, L.R. (1981) Dibutyryl cyclic AMP decreases capacitation time in vitro in mouse spermatozoa. $J$. Reprod. Fert. 62, 63-72.

Fraser, L.R. (1982) $\mathrm{Ca}^{2+}$ is required for mouse sperm capacitation and fertilization in vitro. J. Androl. 3, 412-419.

Fraser, L.R. \& Drury, L.M. (1975) The relationship between sperm concentration and fertilization in vitro of mouse eggs. Biol. Reprod. 13, 513-518.

Fraser, L.R. \& Quinn, P.J. (1981) A glycolytic product is obligatory for initiation of the sperm acrosome reaction and whiplash motility required for fertilization in the mouse. J. Reprod. Fert. 61, 25-35.

Harper, M.J.K. (1973) Stimulation of sperm movement from the isthmus to the site of fertilization in the rabbit oviduct. Biol. Reprod. 8, 369-377.

Johnson, L.L. \& Overstreet, J.W. (1982) Potassium and pyruvate may be regulators of rabbit oviductal sperm motility. Biol. Reprod. Suppl. 1, 26, 145A, Abstr.
Jones, R. (1978) Comparative biochemistry of mammalian epididymal plasma. Comp. Biochem. Physiol. 61B, 365-370.

Mahi, C.A. \& Yanagimachi, R. (1978) Capacitation, acrosome reaction and egg penetration by canine spermatozoa in a simple defined medium. Gamete Res. 1, 101-109.

Mann, T. \& Lutwak-Mann, C. (1981) Male Reproductive Function and Semen. Springer-Verlag, Berlin.

Mrsny, R.J. \& Meizel, S. (1981) Potassium ion influx and $\mathrm{Na}^{+}, \mathrm{K}^{+}$-ATPase activity are required for the hamster sperm acrosome reaction. J. Cell Biol. 91, $77-82$.

Murdoch, R.N. \& White, I.G. (1971) Studies of the stimulating effect of bicarbonate on the metabolism of ram spermatozoa. J. Reprod. Fert. 25, 231-242.

Niwa, K. \& Chang, M.C. (1974) Effects of sperm concentration on the capacitation of rat spermatozoa. J. exp. Zool. 189, 353-356.

Niwa, K. \& Chang, M.C. (1975) Effect of pretreatment of rat spermatozoa with high concentrations of $\mathrm{NaCl}$ on sperm capacitation and fertilization of eggs in vitro. Biol. Reprod. 13, 187-189.

Oliphant, G. \& Brackett, B.G. (1973) Capacitation of mouse spermatozoa in media with elevated ionic strength and reversible decapacitation with epididymal extracts. Fert. Steril. 24, 948-955.

O'Rand, M.G. (1979) Changes in sperm surface properties correlated with capacitation. In The Spermatozoon, pp. 195-204. Eds D. W. Fawcett \& J. M. Bedford. Urban \& Swarzenberg, Baltimore.

Overstreet, J.W. \& Cooper, G.W. (1979) Effect of ovulation and sperm motility on the migration of rabbit spermatozoa to the site of fertilization. $J$. Reprod. Fert. 55, 53-59.

Overstreet, J.W., Cooper, G.W. \& Katz, D.F. (1978) Sperm transport in the reproductive tract of the female rabbit. II. The sustained phase of transport. Biol. Reprod. 19, 115-132.

Overstreet, J.W., Katz, D.F. \& Johnson, L.L. (1980) Motility of rabbit spermatozoa in the secretions of the oviduct. Biol. Reprod. 22, 1083-1088.

Paetkau, V. \& Lardy, H.A. (1967) Phosphofructokinase. Correlation of physical and enzymatic properties. $J$. biol. Chem. 242, 2035-2042.

Peterson, R.N. \& Freund, M. (1973) Effects of $\left(\mathbf{H}^{+}\right)$, $\left(\mathrm{Na}^{+}\right),\left(\mathrm{K}^{+}\right)$and certain membrane-active drugs on glycolysis, motility, and ATP synthesis by human spermatozoa. Biol. Reprod. 8, 350-357.

Pholpramool, C. \& Chaturapanich, G. (1979) Effect of sodium and potassium concentrations and $\mathrm{pH}$ on the maintenance of motility of rabbit and rat epididymal spermatozoa. J. Reprod. Fert. 57, 245-251. 
Rogers, B.J. \& Yanagimachi, R. (1976) Competitive effect of magnesium on the calcium-dependent acrosome reaction in guinea pig spermatozoa. Biol. Reprod. 15, 614-619.

Rogers, B.J., Ueno, M. \& Yanagimachi, R. (1981) Fertilization by guinea pig spermatozoa requires potassium ions. Biol. Reprod. 25, 639-648.

Shams-Borhan, G. \& Harrison, R.A.P. (1981) Production, characterization, and use of ionophore-induced, calcium-dependent acrosome reaction in ram spermatozoa. Gamete Res. 4, 407-432.

Snedecor, G. \& Cochran, W. (1967) Statistical Methods, 6th edn. Iowa State University Press, Ames.

Toyoda, Y. \& Chang, M.C. (1974) Capacitation of epididymal spermatozoa in a medium with high $\mathrm{K}$ / $\mathrm{Na}$ ratio and cyclic AMP for the fertilization of rat eggs in vitro. J. Reprod. Fert. 36, 125-134.
Whittingham, D.G. (1971) Culture of mouse ova. $J$. Reprod. Fert., Suppl. 14, 7-21.

Yanagimachi, R. (1978) Calcium requirement for spermegg fusion in mammals. Biol. Reprod. 19, 947-958.

Yanagimachi, R. (1982) Requirements of extracellular calcium ions for various stages of fertilization and fertilization-related phenomena in the hamster. Gamete Res. 5, 323-344.

Yanagimachi, R. \& Usui, N. (1974) Calcium dependence of the acrosome reaction and activation of guinea pig spermatozoa. Expl Cell Res. 89, 161-174.

Received 25 February 1983 